\title{
Conditioning of the membrane fatty acid profile of Escherichia coli during periodic temperature cycling
}

\author{
Tina Ivancic, ${ }^{1}$ Masa Vodovnik, ${ }^{2}$ Romana Marinsek-Logar ${ }^{2}$ \\ and David Stopar ${ }^{1}$ \\ ${ }^{1}$ Chair of Microbiology, Department of Food Science and Technology, Biotechnical Faculty, \\ University of Ljubljana, Vecna pot 111, 1000 Ljubljana, Slovenia \\ ${ }^{2}$ Chair for Microbiology and Biotechnology, Department of Animal Science, Biotechnical Faculty, \\ University of Ljubljana, Groblje 3, 1230 Domzale, Slovenia
}

Correspondence

David Stopar

david.stopar@bf.uni-lj.si

Received 30 March 2009

Revised 1 July 2009

Accepted 10 July 2009
The membrane fatty acid composition of Escherichia coli becomes conditioned during periodic temperature cycling between 37 and $8{ }^{\circ} \mathrm{C}$. After several cycles of temperature change, the bacteria become locked into a low-temperature physiology. Even after a prolonged incubation at high temperature the membrane fatty acid composition of conditioned cells was similar to that of cold-stressed cells.

\section{INTRODUCTION}

Micro-organisms must constantly adapt to a variety of changing conditions and stresses in their local environment to survive and multiply. In the natural environment, periods of constant temperature or conditions where temperature is up- or downshifted only once, as in a typical cold- or heat-shock experiment, are rare. The driving question of this study is how bacteria adapt their membrane fatty acid composition during periodic temperature cycling. Although the effect of fluctuating temperatures on bacterial growth rate and survival has been demonstrated (Mitchell et al., 1994), there appears to have been no systematic study of how changing temperature during bacterial growth affects membrane composition. In this work we challenge the generally accepted homeoviscous model, which states that membranes consistently adapt to low temperature by increasing the ratio of the unsaturated fatty acids (UFAs) to saturated fatty acids (SFAs) (Sinensky, 1974).

\section{METHODS}

Bacterial growth. In all experiments Escherichia coli strain K-12 was grown in LB (Luria-Bertani) medium, consisting of $10 \mathrm{~g}$ tryptone $\mathrm{l}^{-1}$, $5 \mathrm{~g}$ yeast extract $1^{-1}$ (both from Biolife Italina Srl) and $10 \mathrm{~g} \mathrm{NaCl}^{-1}$ (Merck), in rubber-stoppered tubes on a rotary shaker at 200 r.p.m. in the dark. Bacteria in control cultures were incubated at a constant temperature of $37^{\circ} \mathrm{C}$. In the experiments where temperature was cycled, bacteria were first incubated at $37^{\circ} \mathrm{C}$ for $1 \mathrm{~h}$; cells were then transferred to $8{ }^{\circ} \mathrm{C}$ for $1 \mathrm{~h}$ and so on to the end of incubation. In cold-shock

Abbreviations: C16:0, palmitic acid; C16:1, palmitoleic acid; C17:0cyc, methylene hexadecanoic acid; C18:1, cis-vaccenic acid; SFA, saturated fatty acid; UFA, unsaturated fatty acid. experiments, cells were grown at $37{ }^{\circ} \mathrm{C}$ for $2.5 \mathrm{~h}$ to the mid-exponential phase and were then transferred to $8{ }^{\circ} \mathrm{C}$ with no further temperature change. The temperature of the growth media was monitored every $5 \mathrm{~min}$ by a thermometer coupled to a data logger (Cole-Parmer). The $\mathrm{OD}_{650}$ was measured every 30-60 min with a Multiskan Spectrum microtitre plate reader (Thermo-Fischer Scientific).

$\mathbf{C O}_{2}$ and ATP measurements. Bacterial respiration was measured with a Hewlett Packard 5890 gas chromatograph equipped with a thermal conductivity detector as described previously (Odić et al., 2007). Typically, a $0.25 \mathrm{ml}$ gas sample was taken every 30-60 min during incubation using a $1 \mathrm{ml}$ syringe with a hypodermic needle. The data were corrected for different amounts of $\mathrm{CO}_{2}$ dissolved in the liquid phase at different temperatures. Intracellular content of ATP was measured with an ATP-dependent luciferin-luciferase system as described previously (Odić et al., 2007).

Determination of cellular fatty acid composition by gas chromatography. Cells were harvested by centrifugation and pellets were resuspended in a sterile double-distilled water, frozen $\left(-20{ }^{\circ} \mathrm{C}\right)$ and lyophilized. Lipids were transesterified using the $\mathrm{HCl} /$ methanol procedure (Dionisi et al., 1999). Extracts of fatty acid methyl esters in hexane were analysed on a Shimadzu GC-14A gas chromatograph equipped with a flame-ionization detector. Relative proportions of fatty acids between C10:0 and C20:0 were calculated from peak areas. Identification was done either directly by comparison of retention times of unknown peaks with standard fatty acid calibration mixtures (BAME, MIDI; Sigma-Aldrich) or indirectly by calculation of equivalent chain-length (ECL) factors (Mjøs, 2003).

Statistical analysis. The data were analysed using Student's $t$-test for significant differences between the two sample means $(n>3)$.

\section{RESULTS AND DISCUSSION}

The step-like growth of E. coli during temperature cycling is shown in Fig. 1(a). During temperature downshift from 
(a)

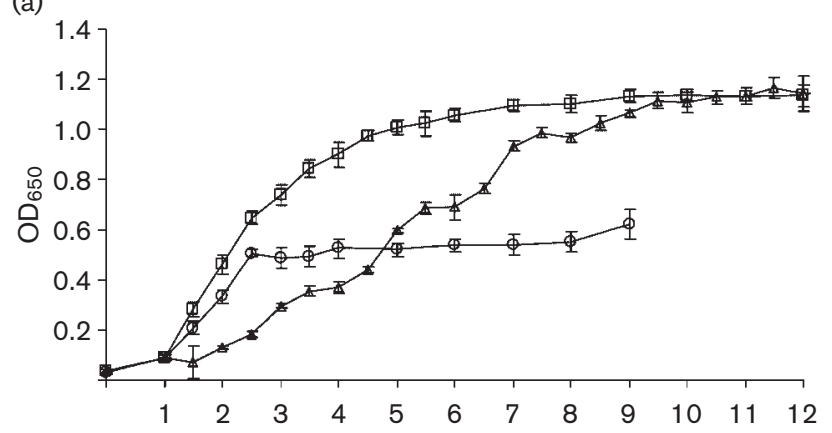

(b)

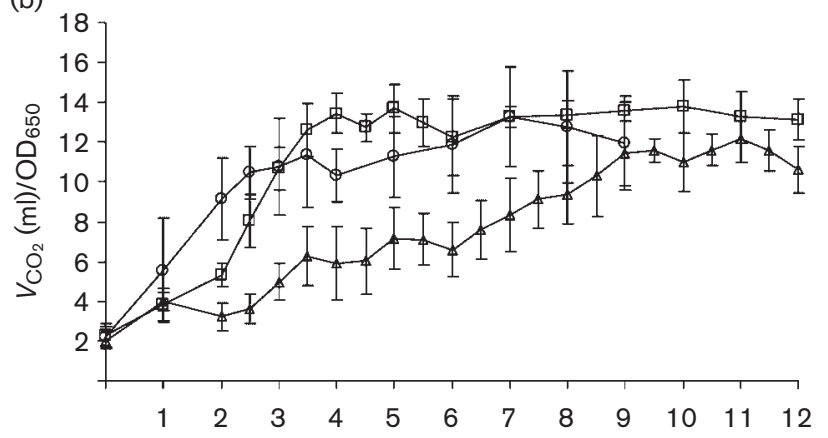

(c)

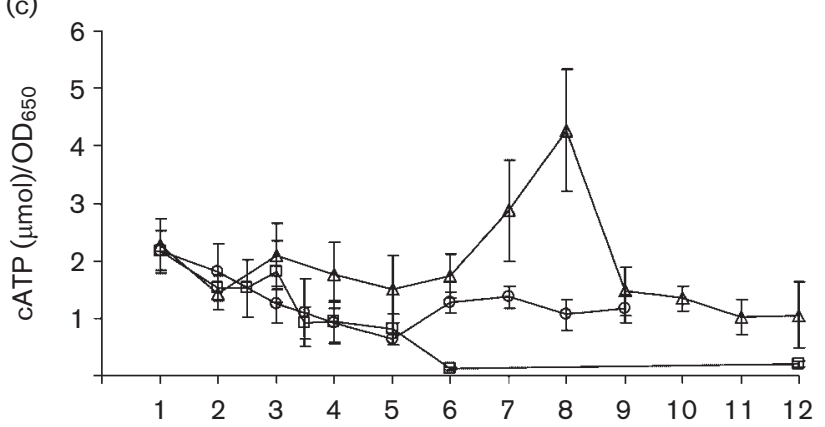

(d)

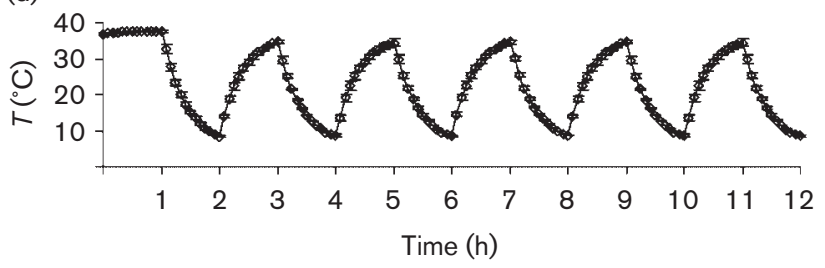

Fig. 1. Growth rate (a), $\mathrm{CO}_{2}$ production (b), and intracellular concentration of ATP (c) of E. coli K-12 during constant incubation at $37{ }^{\circ} \mathrm{C}(\square)$, cold shock $(\bigcirc)$, and periodic temperature cycling between $37{ }^{\circ} \mathrm{C}$ and $8{ }^{\circ} \mathrm{C}(\triangle)$. Samples for $\mathrm{OD}_{650}, \mathrm{CO}_{2}$ production and ATP concentration were taken from the same flasks. Means $\pm S D$ are shown $(n \geqslant 6)$. The temperature profile during oscillations is shown in (d).

37 to $8{ }^{\circ} \mathrm{C}$ bacterial growth stopped after approximately $30 \mathrm{~min}$, when the temperature of the growth medium dropped to $15{ }^{\circ} \mathrm{C}$ or lower. Similarly during temperature upshift growth resumed approximately $30 \mathrm{~min}$ after the onset of temperature upshift, when the temperature in the (a)

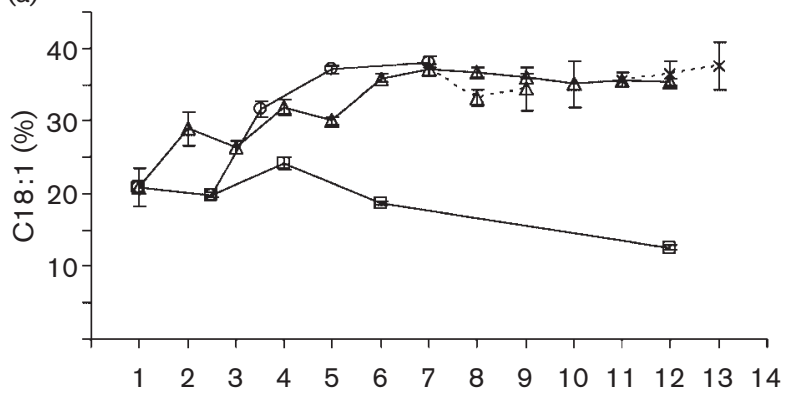

(b)

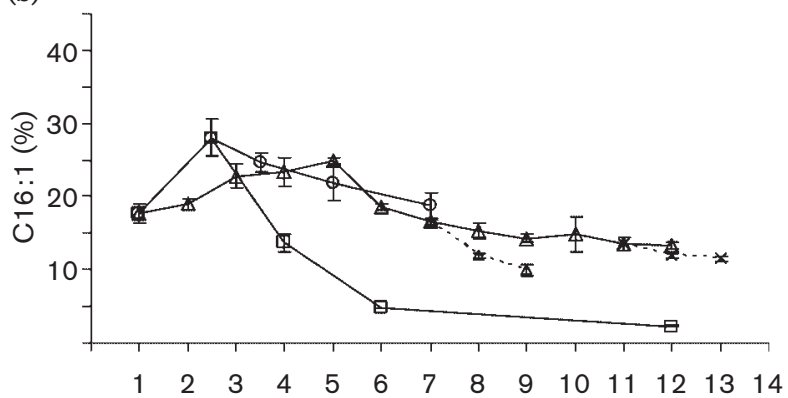

(c)

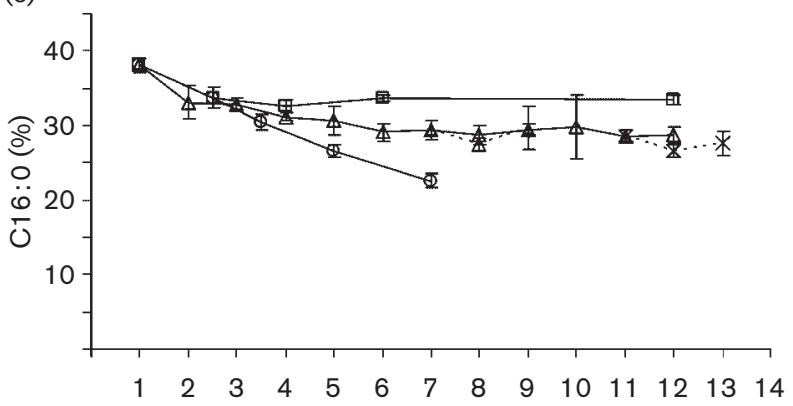

(d)

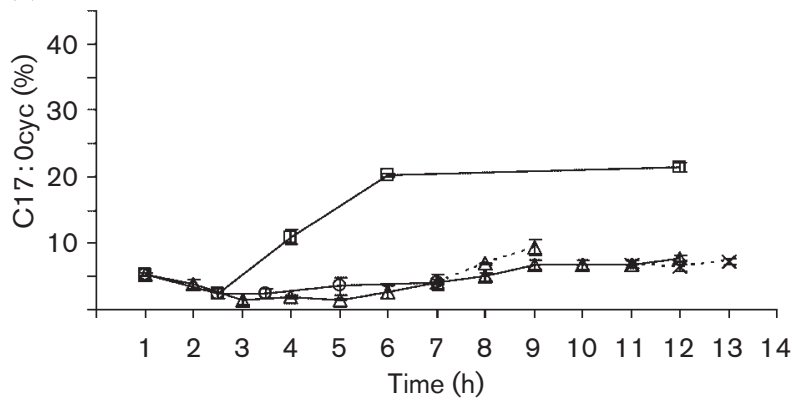

Fig. 2. Fatty acid content of E. coli: C18:1 (a), C16:1 (b), $\mathrm{C} 16: 0$ (c), and C17:0cyc (d) during constant incubation at $37{ }^{\circ} \mathrm{C}(\square)$, cold shock $(\bigcirc)$, and periodic temperature cycling between $37{ }^{\circ} \mathrm{C}$ and $8{ }^{\circ} \mathrm{C}(\triangle)$. The dashed lines represent fatty acid composition after a prolonged incubation at $37{ }^{\circ} \mathrm{C}$ (for $3 \mathrm{~h}$ ) following either three or five temperature cycles. Means \pm SD are shown $(n \geqslant 3)$.

growth medium reached $20{ }^{\circ} \mathrm{C}$ or higher. Production of $\mathrm{CO}_{2}$ (Fig. 1b) correlated with the growth rate during temperature cycling, i.e. more $\mathrm{CO}_{2}$ was produced when 
cells were growing faster and less during slower growth. Unlike growth rate and $\mathrm{CO}_{2}$ production, net ATP concentration (Fig. 1c) did not follow a 120 min period imposed by temperature oscillations. At the end of the experiment periodically fluctuated cells had fourfold higher net ATP concentration than cells constantly incubated at $37{ }^{\circ} \mathrm{C}$. This may indicate that periodically cycled cells were under severe stress (Napolitano \& Shain, 2005).

The response of the fatty acid composition to periodic temperature fluctuations is shown in Fig. 2. During the first two temperature cycles the fraction of unsaturated cisvaccenic acid (C18:1) periodically increased with decreasing temperature and decreased with increasing temperature. With progressing number of temperature cycles $(n>3)$, however, the bacterial membrane lost its ability to change the fraction of $\mathrm{C} 18: 1$ in response to temperature up- or downshift although cells were still able to grow. This is surprising since Garwin \& Cronan (1980) demonstrated that unsaturation is a quick process, completed in less than $30 \mathrm{~s}$, and does not require new protein synthesis. The lack of cell membrane response after three temperature cycles is not what homeoviscous adaptation predicts (Sinensky, 1974) and suggests that periodically oscillated cells maintain a homeostatic response to temperature fluctuations only when they are physiologically young. Not only UFAs but also SFAs changed during periodic temperature fluctuations. The fractions of both palmitic acid (C16:0) and C17:0 cyclopropane fatty acid in temperature-cycled cells were lower than in cells constantly incubated at $37^{\circ} \mathrm{C}$.

An unexpected finding of this study is that the fatty acid profile of periodically cycled cells was more similar to that of cold-shocked bacteria than to that of cells constantly incubated at $37^{\circ} \mathrm{C}$. One would expect either a membrane composition that is intermediate between cold or warm cells or a membrane composition that consistently fluctuates between the two extremes. Neither outcome was observed. It is, however, possible that cells become conditioned not to respond to high temperatures during temperature fluctuations. To test this we extended the time of incubation at $37{ }^{\circ} \mathrm{C}$ after cells had completed either three or five temperature cycles. There was no change of fatty acid composition with prolonged incubation at $37^{\circ} \mathrm{C}$, when cells were already in the stationary phase (Fig. 2, dashed lines). This indicates that membrane fatty acid composition of stationary-phase cells is rather fixed and is not responsive to temperature fluctuations. Although the situation was slightly different when cells had completed three temperature cycles, the cells were still not able to revert to the membrane fatty acid composition of cells constantly incubated at $37{ }^{\circ} \mathrm{C}$. This result suggests that the membrane fatty acid composition of $E$. coli becomes conditioned to cold during periodic temperature cycling.

\section{ACKNOWLEDGEMENTS}

We gratefully acknowledge financial support from the Slovenian Research Agency (ARRS no. 1000-06-310164).

\section{REFERENCES}

Dionisi, F., Golay, P.-A., Elli, M. \& Fay, L. B. (1999). Stability of cyclopropane and conjugated linoleic acids during fatty acid quantification in lactic acid bacteria. Lipids 34, 1107-1115.

Garwin, J. L. \& Cronan, J. E., Jr (1980). Thermal modulation of fatty acid synthesis in Escherichia coli does not involve de novo enzyme synthesis. J Bacteriol 141, 1457-1459.

Mitchell, G. A., Brocklehurst, T. F., Parker, R. \& Smith, A. C. (1994). The effect of transient temperatures on the growth of Salmonella typhimurium LT2. I: cycling within the growth region. J Appl Bacteriol 77, 113-119.

Mjøs, S. A. (2003). Identification of fatty acids in gas chromatography by application of different temperature and pressure programs on a single capillary column. J Chromatogr A 1015, 151-161.

Napolitano, M. J. \& Shain, D. H. (2005). Distinctions in adenylate metabolism among organisms inhabiting temperature extremes. Extremophiles 9, 93-98.

Odić, D., Turk, V. \& Stopar, D. (2007). Environmental stress determines the quality of bacterial lysate and its utilization efficiency in a simple microbial loop. Microb Ecol 53, 639-649.

Sinensky, M. (1974). Homeoviscous adaptation - a homeostatic process that regulates the viscosity of membrane lipids in Escherichia coli. Proc Natl Acad Sci U S A 71, 522-525.

Edited by: F. Sargent 